\title{
Impacts of climate change and ecological restoration programs on vegetation activity dynamic in the Mu Us Desert, China
}

\author{
Sun Zenghui ${ }^{1}$, Liangyan Yang ${ }^{2}$, Huanyuan $\mathrm{Wang}^{2}$, Zhe $\mathrm{Liu}^{2}$, and Jichang $\mathrm{Han}^{2}$ \\ ${ }^{1}$ Shaanxi Provincial Land Engineering Construction Group Co., Ltd \\ ${ }^{2}$ Shaanxi Provincial Land Engineering Construction Group Co., Ltd.
}

June 15,2020

\begin{abstract}
As an important component of terrestrial ecosystems, vegetation is a commonly used indicator to evaluate climate change and ecological restoration efforts. In the farming-pastoral zone in China, the Mu Us Desert is a typical area utilizing desertification control methods where vegetation cover has significantly changed. However, few studies have considered vegetation changes due to multiple factors in this region. In this study we investigated spatiotemporal variations in vegetation cover in the Mu Us Desert (including 11 counties) from 2000 to 2019 using Normal Difference Vegetation Index (NDVI) time-series data. Our results indicate that NDVI during the growing season (May to October) across the whole region increased by 0.0058 per year during the 20-year study period. Correlation analysis between NDVI and climatic factors indicated that precipitation, temperature and relative humidity had a significant positive correlation, and mean wind speed and sunshine hours had a significant negative correlation across the study area (except for mean wind speed in Shenmu and Yuyang). Climatic and ecological restoration had a $44 \%$ and $61 \%$ effect on NDVI change in the study region, respectively, indicating that the ecological restoration program played a dominant role in driving NDVI in the majority of counties in the Mu Us Desert from 2000 to 2019 . Findings from our study may help to reveal the dynamics of the ecological environment, providing valuable information for decision making concerning vegetation resources management and further ecological restoration measures in other similar desert areas.
\end{abstract}

\section{Hosted file}

LDD-submit-20200615.docx available at https://authorea.com/users/333558/articles/459733impacts-of-climate-change-and-ecological-restoration-programs-on-vegetation-activitydynamic-in-the-mu-us-desert-china 

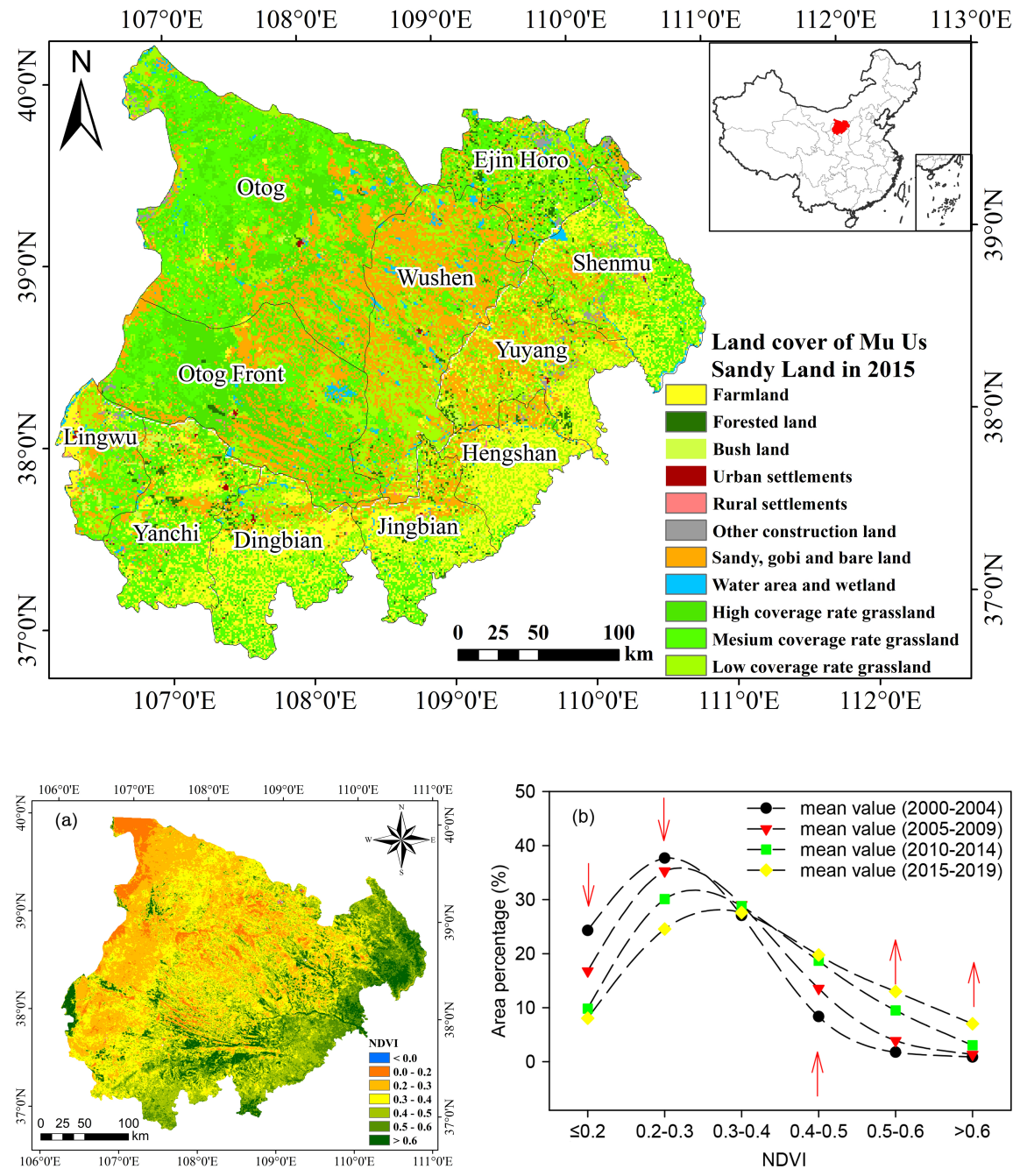

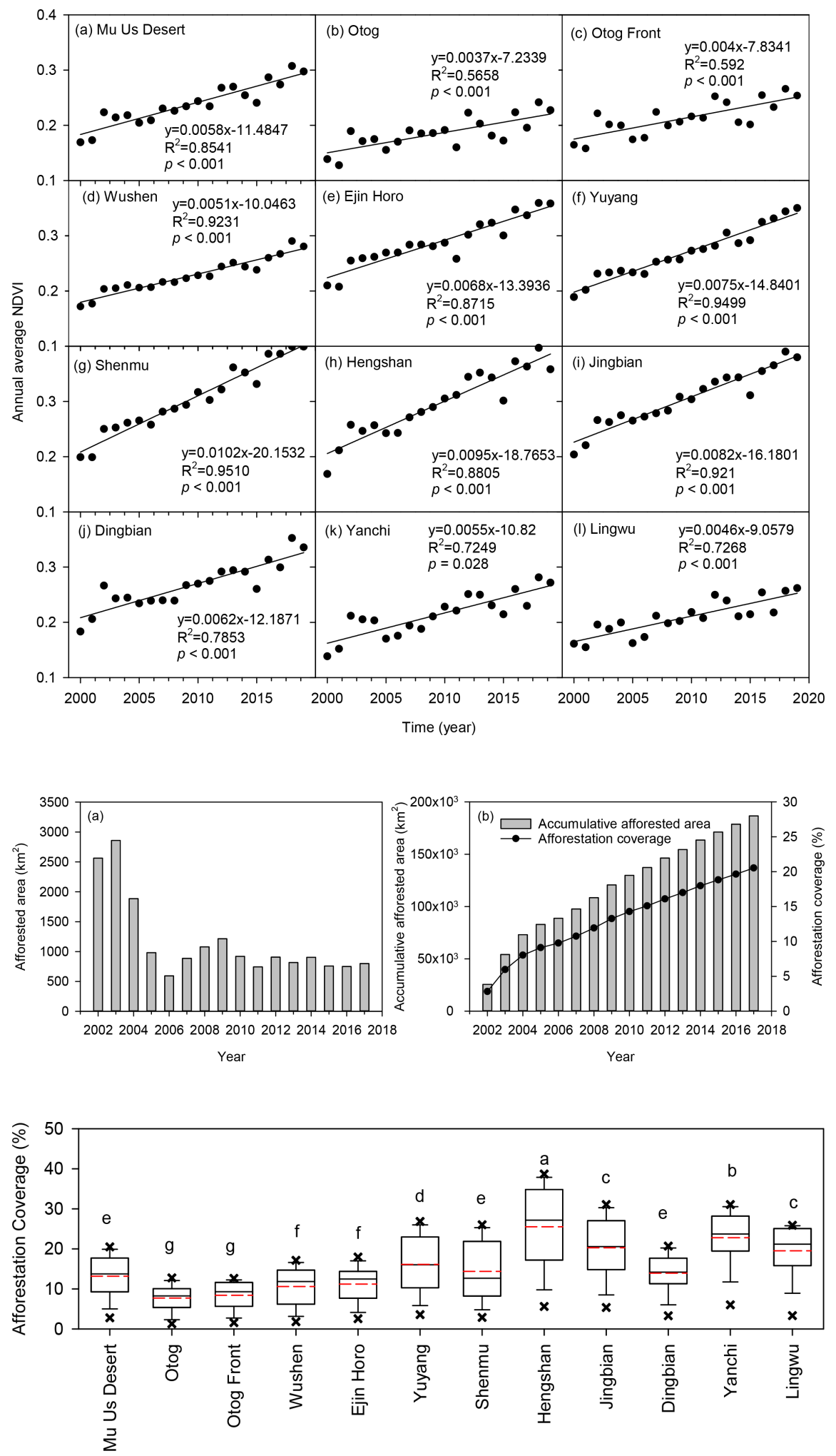


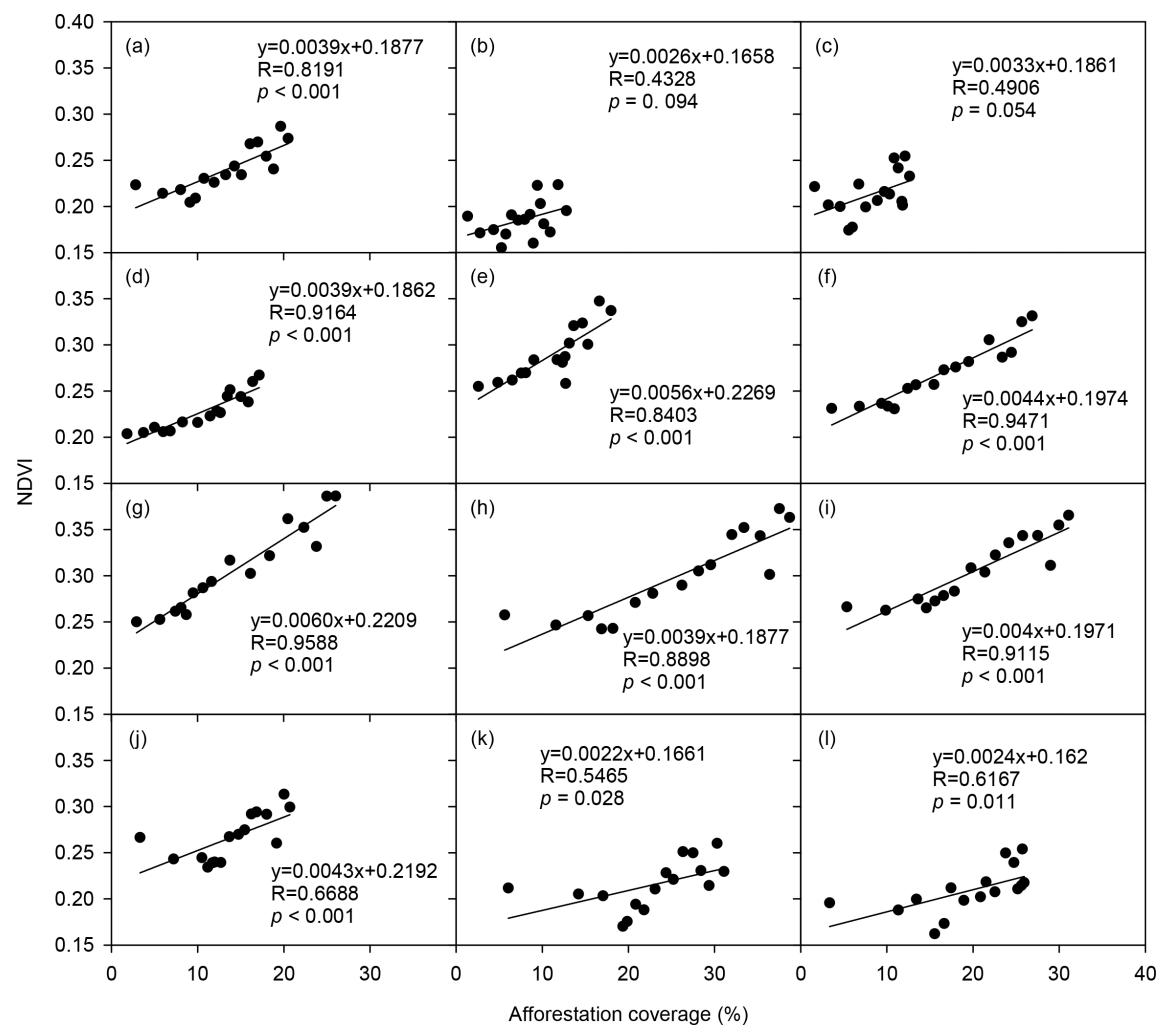

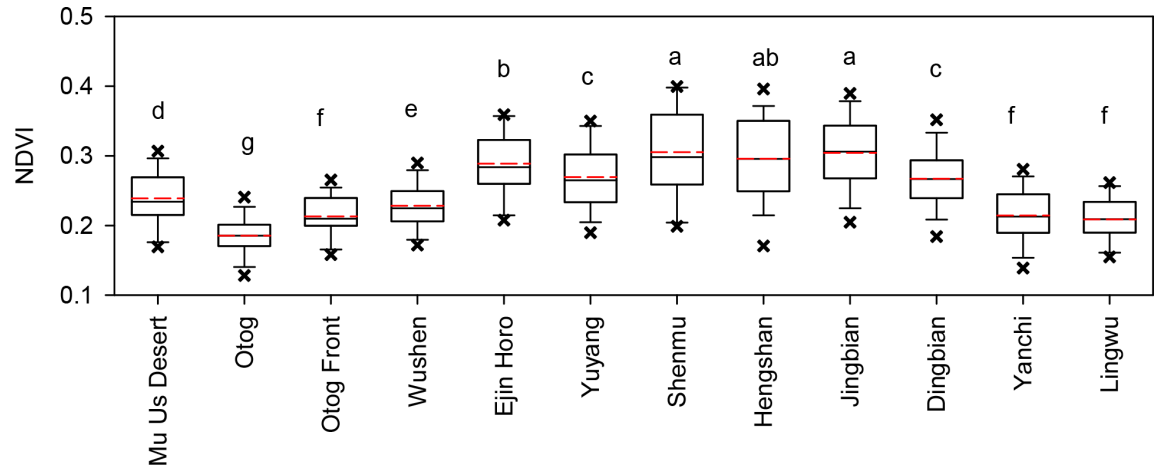

